\title{
Negotiating Contestations for Community-Oriented Heritage Management: A Case Study of Loushang in China
}

\author{
Xiaomei Zhao \\ Department of Cultural Heritage and Museology, Fudan University, Shanghai, China \\ Email: zhaoxiaomei@fudan.edu.cn
}

\begin{abstract}
Rural heritage is a living heritage of significant importance; it requires community-oriented management for cultural continuity and local development. Different social relations exist at rural heritage sites, which lead to external contestation among stakeholders and internal contestation within the community. It is essential to identify the impact caused by such contestations and determine an appropriate way to negotiate solutions. This paper examines the case of Loushang in Guizhou Province, identifying the contestations by examining the social relations through questionnaires and semi-structured interviews. Negotiation requires an appropriate person or social group to act as intermediary: they engage the stakeholders and induce them to collaborate; they also empower the community in heritage management. The case of Loushang indicates the tools that are necessary to facilitate community-oriented management for rural heritage; it bridges theoretical research and heritage practice.
\end{abstract}

KEYWORDS internal contestation, external contestation, community-oriented heritage management, rural heritage

Received November 27, 2017; accepted August 2, 2019.

\section{Introduction}

Community is an indispensable component of living heritage (Baillie 2009). In the case of rural heritage, the community refers to local people, who live in the village, perform their daily routines, and produce and reproduce their social relations and cultural products. It is the locals who give value to a heritage site. Community-oriented heritage management is necessary, whereby the community is empowered both to participate and make decisions for itself.

In China, rural heritage is officially designated by the state. Conservation of such official heritage is primarily a government-led, professional practice guided by legislation (Harrison 2013). Nevertheless, empowerment of a heritage community and its participation in management has been encouraged ${ }^{1}$. With such villages, the stakeholders usually include community members (who live on-site and create its heritage value), the local government (which administers the site), and heritage experts (who are committed to conservation work). Heritage is regarded as cultural capital and a touristic resource by local governments; thus, it attracts investors, who establish companies to manage heritage tourism, usually under the supervision of local governments. Further, tourists, who appreciate the value of the heritage created by a community, visit and become stakeholders; they consume tourism resources (not limited to the official heritage) provided by the particular company. Contestations may take place among the stakeholders (Li and Wang 2013): such conflicts have been examined from the perspectives of heritage studies, anthropology, archaeology, and tourism studies. Unlike external contestation among stakeholders, internal contestation is a topic that hitherto has often been neglected. In previous research on heritage management, a community has usually been viewed as a unified collective; however, that situation does not apply to the complexity of social relations associated with rural heritage.

The above contestations have led to many social and cultural problems in heritage management, such as identity and attachment. Dealing with those disputes demands careful examination of the social relations. In heritage practice, empowerment of the community regarding its own heritage management is required. There is still a considerable gap between theoretical studies and instrumental tools: interdisciplinary critical reflection of heritage studies is urgently needed. 
Focusing on the hamlet of Loushang, which has a Han population (a minority in Guizhou), I examine two types of contestations: external among the stakeholders; and internal within the community. Situated in Southwest China, Guizhou has the greatest ethnic diversity of any province. Thus, the Han hamlet constitutes a minority community in a region that is characterised by many ethnic minorities. In Loushang, the contestations are rooted in its geographical location, which has fostered cultural diversity and a long history of ethnic interaction. In recent decades, remarkable social changes have taken place in Guizhou-especially regarding government efforts to promote Han tourism to ethnic minority regions. The Han migrant villages in Southwest China, including Loushang, where Han people have resided for centuries, are also destinations for such Han tourists. The data collected from a questionnaire survey and interviews conducted with different social groups ${ }^{2}$ pointed to tensions between the majority and minorities as well as between official heritage managers and local residents.

This paper examines two interconnected issues caused by the contestations. The first is Han identity in the minority region as manifest through heritage performance. The second is locals' attachment to their shared heritage. Both issues are affected by external and internal contestations, which pose a potential threat to the continuity of heritage values.

Identification of the issues, negotiations among stakeholders, and empowerment of the community are the main tools towards reducing the negative impacts of those contestations and achieving community-oriented management of the rural heritage. Accordingly, I first distinguish the community and stakeholders of Loushang, recognising their social relations. Second, I identify the two types of contestations: I explain their impact on attachment and identity. Based on the fact that intermediaries can negotiate these contestations, this study aims to identify those intermediaries and examine their potential contributions. In the final part of this paper, I propose ways to empower the community through exhibition curation and industrial development-with the help of intermediaries and collaboration among the stakeholders.

The goal of this case study is to provide an interdisciplinary application of the above-mentioned tools in heritage practice for community-oriented management: in that way, cultural and social problems in rural heritage can be addressed, and the community can manage its own heritage. This heritage practice is inspired by and based on theoretical thinking; however, crucially, it also bridges the gap between academic researchers and heritage practitioners.

\section{Community-Oriented Heritage Management for Rural Heritage}

Heritage management is essential for cultural continuity and social maintenance, which are required by regulations for official heritage sites. Generally, China's heritage management is authorised by government administrators and professionals. When a heritage site becomes officially designated, a professional team is assigned by the government to preserve the heritage ${ }^{3}$. This means that the team seeks to work with the community to preserve its tangible heritage and restrict construction work there, such that the local built environment is not greatly altered. I was part of a team sent to Loushang to compile a conservation master plan. Accordingly, the budget for conservation projects (including restoration, renovation, and disaster prevention) was financed by the governmental administration ${ }^{4}$. Those projects were implemented by professional practitioners. The government promotes both tangible and intangible heritage conservation as well as the sustainability of heritage practices in rural villages. Those practices may be termed 'traditions' owing to the official interest in them on the part of the government and the community in addition to the built environment. Daily care (including maintenance of physical structures as well as continuity of local culture and social reproduction) is a significant part of heritage traditions. However, unlike the massive funding made on conservation projects, daily care is insufficiently financed-both with respect to assigning professional practitioners and training the community. In typical cases, tourism investors seize the opportunity by appointing their own company to take charge of heritage management under local government guidance.

For the heritage value of the community, management of rural heritage has to be community oriented. Empowerment of locals is essential to heritage practice in China (Luo 2016; Wang 2016). However, research on this topic is comparatively scarce. Villages are treated as cultural capital to improve the local economy and governance in China (Oakes 2013; Wang 2017) ${ }^{5}$. A number of international scholars have studied China's villages since the early 1990s. Oakes (1995, 1997, 2006, 2009, 2010, 2013, 2016) and Tapp $(2008,2010,2014)$ are the two most productive and inspiring overseas scholars in studies of ethnically diverse Southwest China. The new millennium has seen more studies by Chinese scholars from overseas institutes, 


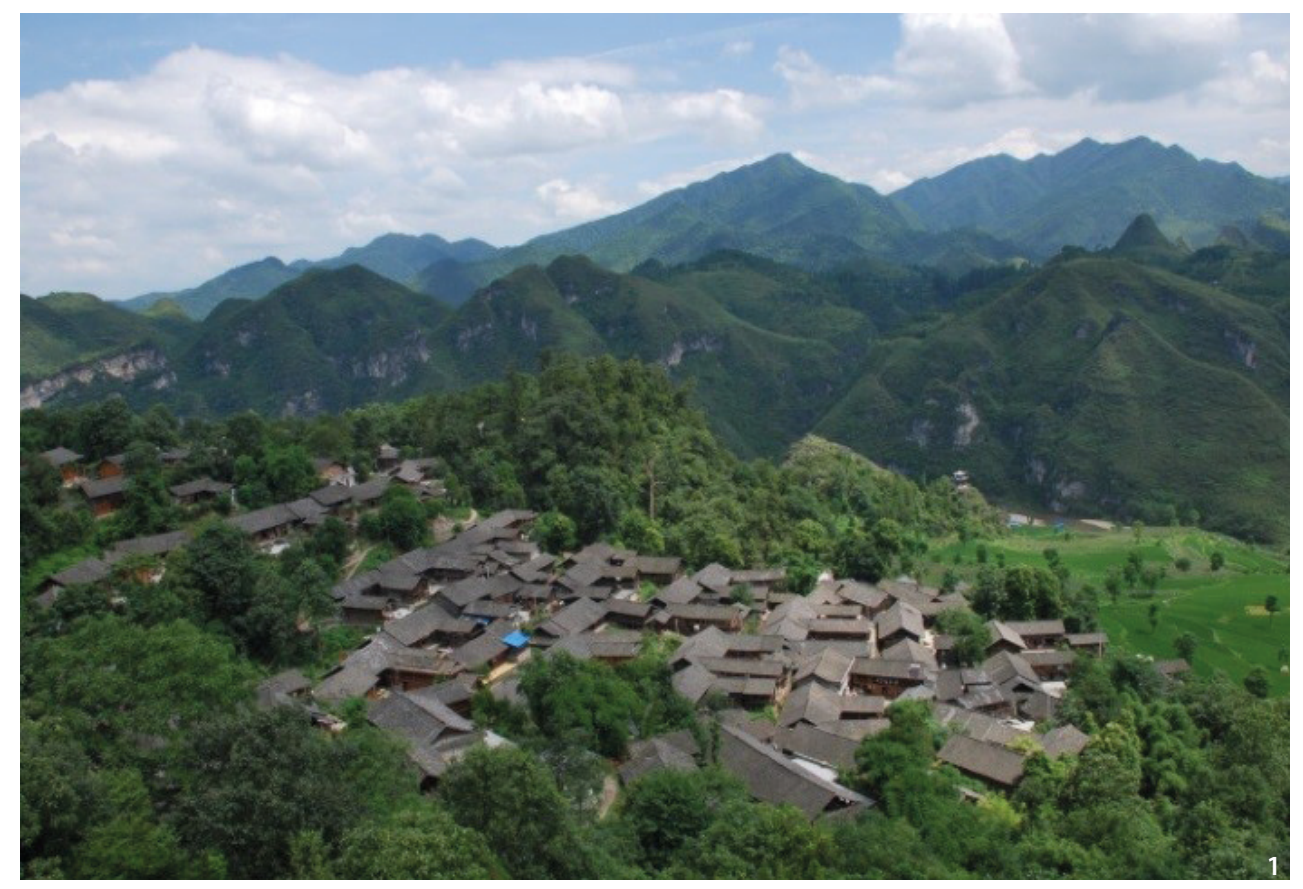

Figure 1 Loushang Village and its surrounding mountains (Source: the author).

such as research on Fujian by Yan (2012, 2015), Hunan by Yu (2015), and Yunnan by Zhu (2015). The researchers provide critical views of cultural heritage and stimulate reflections on conservation practice. However, few of those authors have had practical experience in grounded conservation, such as conservation master plans and restoration work. Moreover, internal contestation is seldom discussed within a community.

In line with conservation regulations, heritage practice is mainly conducted by institutional practitioners. Trained in architecture and urban planning, most practitioners lack critical insight into community empowerment through heritage studies in the social sciences. A multiinterdisciplinary survey has been conducted by such practitioners and their working practices: the work is systematically designed according to official heritage criteria and mechanically performed over a space of only a few days owing to time limits for such projects ${ }^{6}$. As a result, the outcomes are not in keeping with locals' understandings of their own heritage. However, the heritage practice in Loushang is an exception.

In brief, existing research on community-oriented heritage management for villages has two shortcomings. First, contestation is mostly identified among the stakeholders: internal contestation goes unnoticed within the complex rural heritage. Second, academics are frequently often absent in heritage practice. This paper examines both external and internal contestations, and it employs academic techniques in a real-case scenario.

\section{Research Setting and Methods}

Loushang is a Han migrant hamlet of over 400 people from almost 100 households (Figure 1) ${ }^{7}$. It is the home of the Zhou clan of neighbouring Han villages-even though the region is dominated by the ethnic minorities of the Miao (Hmong), Dong (Kam), and Kelao. The majority Zhou clan has both collaborated and contended with those ethnic minorities while persisting in maintaining its Han identity. The culture in Loushang is the result of a long history of ethnic interaction.

The research presented in the present paper is based on the findings from a conservation project undertaken by a team and conducted in Loushang. The project was commissioned by the local government, and the team members (including myself) were engaged ethnographers (Stevens, Flinn and Shepherd 2010; Carlarne 2011; Urla and Helepololei 2014) rather than professional practitioners. We conducted long-term fieldwork and interdisciplinary collaboration to determine the various opinions within the community and among stakeholders. Our team had several stays in the village: three weeks in August 2016; one week in January 2017; and one week in February 2017. The team of 19 researchers comprised the following: two scholars on heritage conservation; one on cultural landscape; one on museology from the Faculty of Cultural Heritage and Museology of Fudan University; nine graduate students from the same faculty; four students majoring in architecture, landscape, and planning from other universities; and two architects from another institute. 
We undertook different ways of communicating with community members and stakeholders. We distributed a questionnaire to 86 households, covering every village resident except for eight households whose members were away from home during our fieldwork. The questionnaire gave all the locals an equal chance to voice their opinions (Riesto and Tietjen 2016). The semi-open questionnaire obtained quantitative and qualitative information about the household, such as family structure, genealogy, type of housing, type of farming, religious beliefs, and education. The questionnaire was executed in the form of one team member reading out the questions to the residents: a translation between Mandarin and the local dialect was conducted by local youths, who acted as intermediaries between the community and the researchers. In that way, we were able to present open-type questions and establish good relations with the locals. The questionnaire also included items related to demands and proposals for improving living conditions. Participant observation was conducted during the Spring Festival in 2017 to determine how the villagers were socially organised at such ceremonies. As part of our fieldwork, we provided feedback and opinions to the community: that served to enhance communication and negotiation-especially with regard to issues related to preservation work, infrastructure renovation, tourism investment, and industrial development.

We conducted interviews with the following individuals to assess the diversity of social roles in Loushang and nearby Zhou villages: leaders of Loushang (two village cadres and four group leaders); carpenters (one for housing and the other for furniture and other items); geomancers (fengshui practitioners); intellectuals (two teachers at local schools and one professor at a regional university); and private tourism business operators (four owners of restaurants and lodgings). We used slightly different structured questions for those people according to their knowledge of the heritage; the questions covered issues related to the past, present, and possible future of the village.

We interviewed other stakeholders who held official or semi-official occasions. At several official meetings, we asked the town and county cadres for their opinions and advice about local development. We also interviewed two tourism investors and managers about their investment plans.

Communication with community members and other stakeholders helped us understand their different demands and identify the contestations-both among the stakeholders and within the community. It was important to identify the various impacts and attempt to solve the disputes before inducing the community to collaborate in heritage management.

\section{Community and Stakeholders of Loushang}

There were different social relations within the community and among the stakeholders. Their contestations led to two interconnected issues: the Han identity in a minority region; and Han attachment to the shared heritage. We made a search for intermediaries who could facilitate negotiations.

\section{Community}

The local inhabitants are the core community in Loushang. They are not limited to hamlet residents but include clansmen living in nearby settlements who share a common ancestor. According to the 'Genealogy of the Zhou Clan' in and around Loushang, Boquan was the first local ancestor, having settled in Loushang at the end of the $15^{\text {th }}$ century $^{8}$. That Han family originally came from Jiangxi Province and moved to the southwest minority region; they did so because in the early Ming Dynasty (1368-1644), Boquan received an official appointment in Sichuan Province. Subsequently, Boquan's descendants never returned to their homeland in Central China but migrated farther within the southwest (Figure 2). They were part of a massive Han migration into that minority region. Loushang is situated on what was the official courier route established by the central government for connection with the southwest frontier (Shi 1990). The Zhou family purchased the Loushang land from the local Miao people ${ }^{9}$. Since then, the Zhou clan has expanded to form several settlements nearby.

To survive in this new environment of exotic cultures and compete for limited environmental resources, the Han migrants had to learn from the local minorities. They also allied with other ethnic groups to fight against local government repression. As a result, the culture in Loushang is a fusion of both Han traditions and local minorities' customs. For example, household courtyards are in accordance with the Han ideal housing model-even though the hamlet is located on a mountainside and the setting is inappropriate for constructing a courtyard house. However, the building structure and materials are local. Overall, the physical space represents a combination of Han traditions and minority influences. 


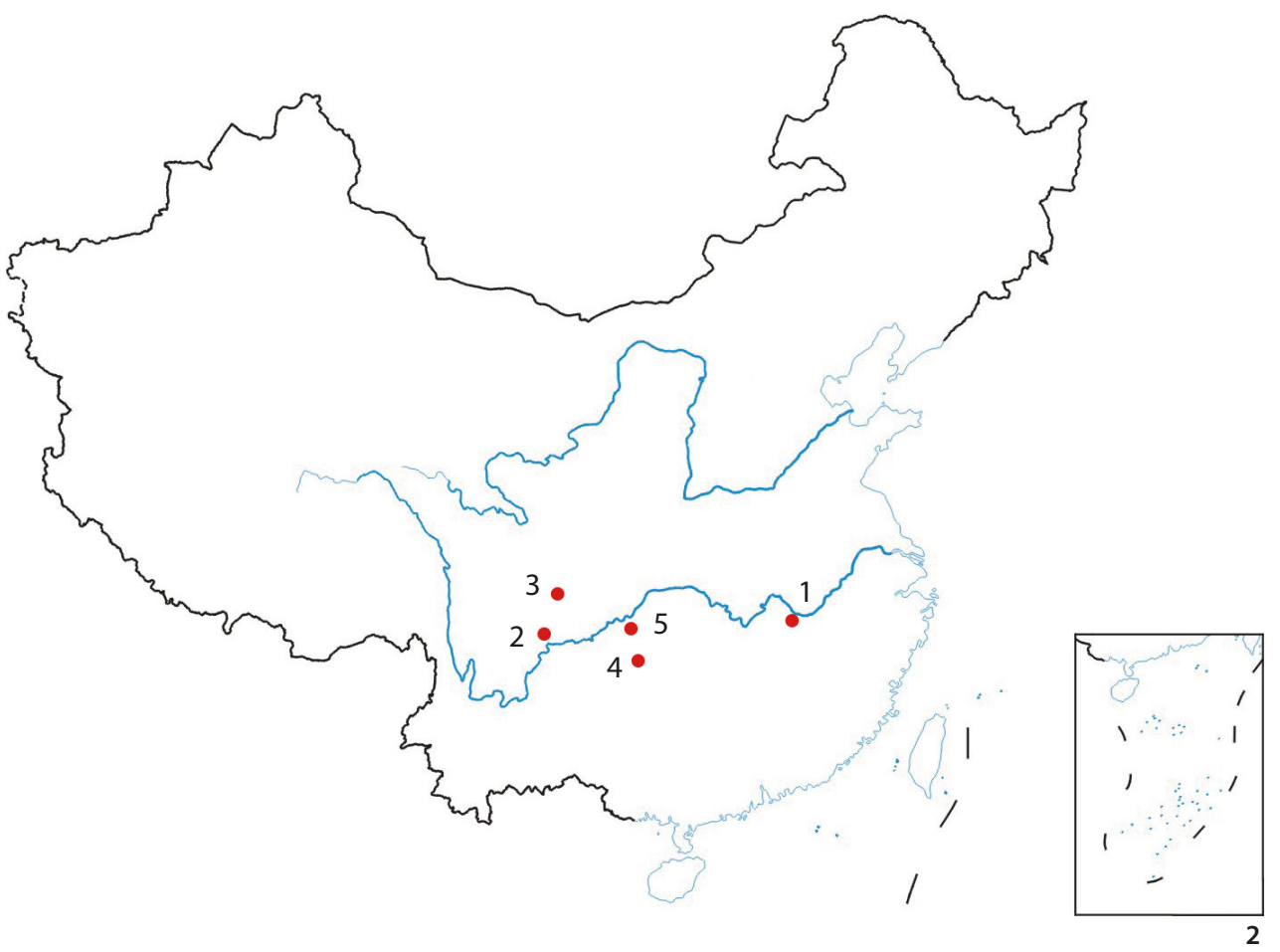

Migration Route

1. Nanchang in Jiangxi

2. Jiading in Sichuan

3. Tongchuan in Sichuan

4. Zhenyuan in Guizhou

5. Loushang in Guizhou

Figure 2 Migration route of the Zhou clan ancestors in Loushang (Source: the author, map approval code: GS[2019]5564 ).
A similar situation is evident with religious beliefs and ceremonies. Most minority villages consist of homogeneous houses and lack a public space. By contrast, the Zhou clansmen in Loushang have erected several monumental buildings-just as the Han always do in their homeland. Zitong Temple is located in Loushang, and an ancestral temple has been built in the centre of the surrounding Zhou hamlets. With Zitong, the deity was originally one of the local minorities and the temple features an auxiliary space for ancestral rituals. The ancestral temple (Figure 3) in surrounding hamlets is a sacred place for ancestral rituals and is significant for the entire clan. During the Qingming Festival (5 April), all the clansmen hold a grand ceremony for their common ancestors. They transfer memorial tablets from the ancestral temple to Zitong Temple (Figure 4) and hold celebrations in the auxiliary space ${ }^{10}$. In homes, the ancestors of the household are enshrined at the centre of the principal room, and incense is offered to them every day. In these ways, the Han preserve their identity in physical spaces in a manner we refer to as 'heritage'. For the clansmen, preserving this tangible heritage serves as a kind of attachment to their shared home. This attachment-constructed and reinforced through the struggles of their Han identity in the minority regionadds unique value to this rural heritage site.

However, the clansmen do not constitute a solid unity. They comprise different branches and generations; they have different occupations and educational backgrounds. Thus, there are varied social relations within the community. A combination of competition and collaboration exists among the social groups, and it affects their attachment to the village.

In the present research, the younger generation was a main focus. Members of that generation collaborated with us in our fieldwork, and we exchanged opinions. The young people also functioned as intermediaries among the various social groups and facilitated discussions within the community.

\section{Stakeholders}

Thanks to its living culture and beautiful landscape, Loushang has become a national cultural heritage, attracting the attention from the local government and investors. The hamlet is considered a tourist resort, and a tourism company has been established, which is supported by the local government. Thus, various stakeholders in Loushang have emerged. The locals live on-site and maintain their heritage. The local government is responsible for conservation of the designated official heritage, and it supervises tourism development. The tourism company oversees tourism management of the village, and it also invests in eco-agriculture and other industries. The visitors (mostly Han Chinese from the local region and beyond) are the recipients of information and services at the site, which 


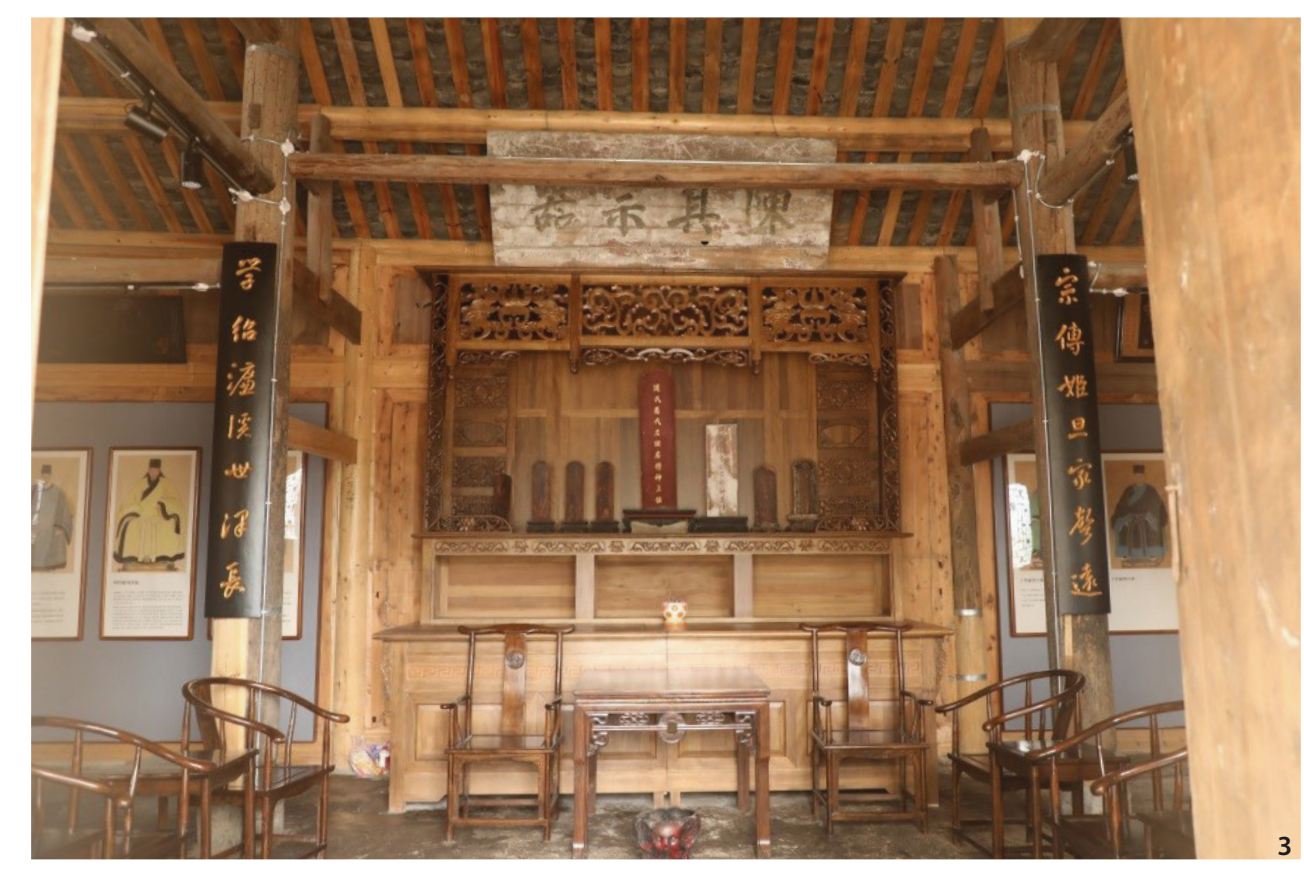

Figure 3 The ancestral temple for the Zhou clan (Source: Keshuo Cao).

Figure 4 Zitong Temple in Loushang (Source: Keshuo Cao).

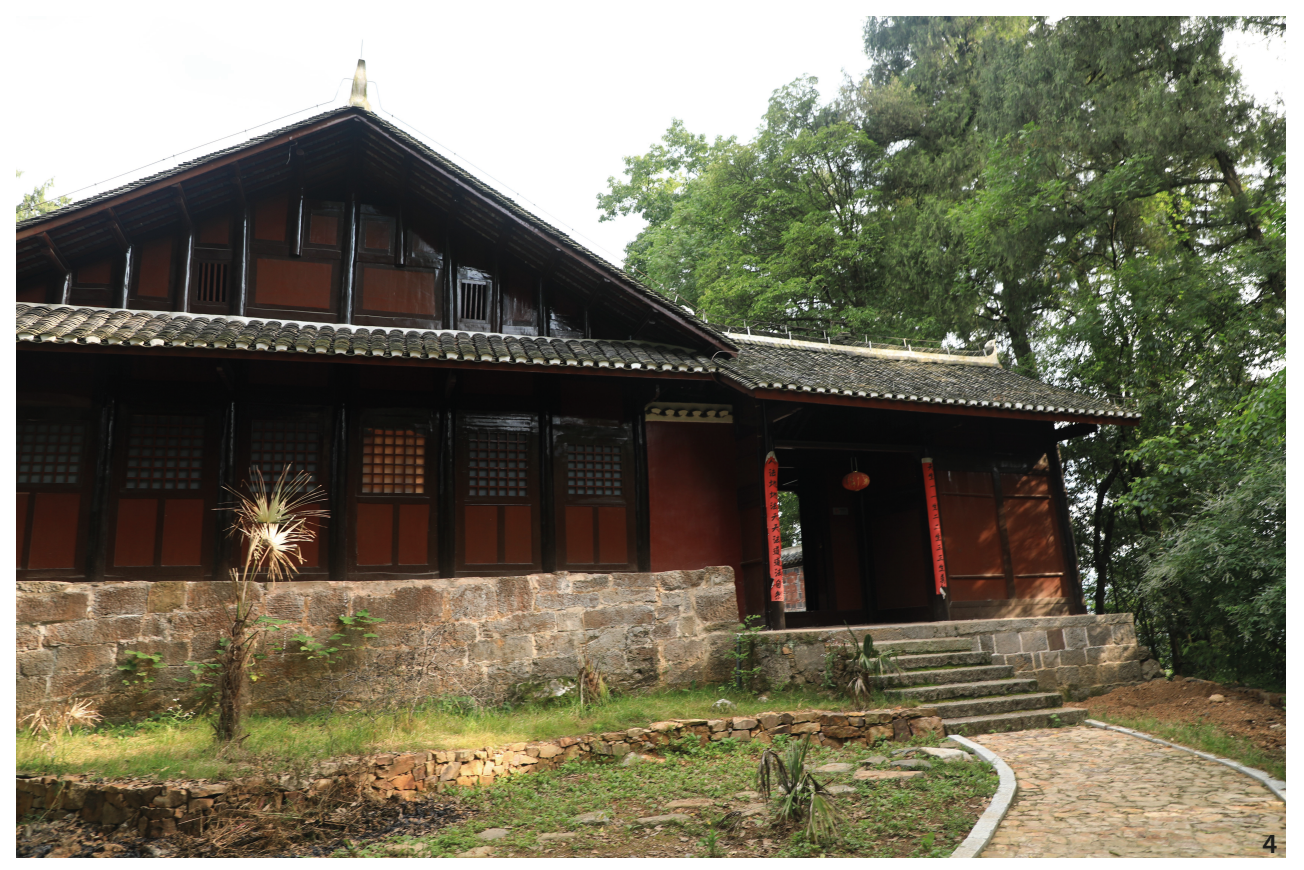

is offered by the community and the company under government supervision.

Those are the main stakeholders in Loushang, and they are connected by the heritage value of the living culture in this Han migrant village. In general, the government (as the heritage policy maker) preserves the value of the village and presents it to visitors. The company invests in the heritage value and sells it to the visitors (following government guidelines). The visitors appreciate that value. The community creates the value; however, in the current situation, the community scarcely benefits owing to its lack of involvement in heritage management. This situation has to be improved through negotiations among the stakeholders; in that process, a proper intermediary person is required.

Before the modern time, members of the local gentry (see the definition in Fei 1985) such as intellectuals and hamlet leaders acted as intermediaries whenever a conflict took place between the government and local residents, among ethnic groups and villages, and among branches within the same clan. In Loushang today, the intermediary is a woman from the outside the community (hereafter referred to as ' $L$ '), who moved to the hamlet and worked there for years. She has considerable 
knowledge about contestations among the stakeholders, has a strong connection with all of them, and works actively in discussions.

\section{External Contestation: Han Identity as Ethnic Tourism Resource in Guizhou}

The local government and tourism company work closely together to promote the ethnic culture of Loushang. Owing to its location in the minority region, Loushang was falsely presented as a Dong village at the beginning of tourism investment in the early 2000s. Han locals were asked to dress up like the Dong and put on Dong performances-even though they have never identified themselves with that ethnic group. Those residents fully understood the situation and compromised by exhibiting false ethnic cultural elements. The rights of visitors, who were unaware of the true situation, were ignored by other stakeholders.

That early investment failed to succeed: few tourists visited to increase the local income. The failure diminished the villagers' confidence and patience with tourism investment. A decade later, the hamlet was finally promoted in the ethnic touristic market as one of Han migrants, and a new round of tourism investment began. However, that move produced more contestation. The official heritage (both tangible and intangible) was adopted only as a kind of 'cultural fossil', ignoring the interaction that has long existed among the different ethnic groups. The value of the living culture is currently being improperly preserved and presented. The previous leading role of the community in daily care of the village has been replaced by that of other stakeholders, which has had an impact on their attachment to their own homeland.

\section{Qingming Festival: Worship or Collective Performance}

Ancestral worship is essential in Han traditions. Worshipping their ancestors during the Qingming Festival is the biggest event for the Zhou clansmen. Formerly, the clan leaders coordinated the rituals conducted among the different branches. The ancestral ceremony served to unify Zhou clansmen in and around Loushang and to help maintain their Han identity in that minority region.

That celebration initiated by the clansmen has now, however, been transformed into a show organised by the government and tourism company, and it is performed by the community. The participants are school students in school uniform under the direction of their teachers-rather than families of different branches following clan leaders. For that celebration, those boys and girls undergo so-called traditional education. That has had the effect of converting it into a ceremonial event, whose attendants include regional celebrities and media journalists. It is no longer a community-initiating celebration to reinforce the residents' identify. The celebration has been deprived of its social function, whereby the clansmen competed and compromised. The official coordinators make all the arrangements. The clansmen have been reduced to performers for a much larger audience onsite and via the media. Visitors witness only a gorgeous performance, not a living culture in its natural state. The celebration produces benefits only for tourism investment, not for heritage practice or cultural continuity.

\section{Dragon Lantern: Tradition or Intangible Heritage}

In the southwest minority region, the Han migrants absorbed the customs of other ethnic groups; in the process, those customs became incorporated into their own tradition. However, this type of mutual learning is not acknowledged in cultural heritage presentation, such as in the case of dragon lanterns. The lanterns are made of bamboo and played by a dozen of players with drumbeats. Playing dragon lanterns is a common celebration in festivals in the county where Loushang is located: the lanterns are played by several ethnic groups, including the Kelao, Dong, Miao, and Tujia. In Loushang and its nearby Han villages, the lanterns are played during the Spring Festival when Loushang residents visit their neighbouring villages ${ }^{11}$. This phenomenon explains why different ethnic groups have adopted the same tradition: they must have learned the custom from reciprocal visits during festivals. Dragon lantern playing is believed to have originated with the Kelao in Guizhou (Zhang, Wang and Tang 2014). Unlike the Kelao, who play the lanterns only during the Spring Festival, the Han migrants also undertake it during the Qingming Festival to amuse their ancestors. As a result, the meaning attached to lantern playing has changed: for the Zhou clan, it is believed to bring peace and health; for the Kelao, it is a form of bamboo worship (Zhang, Wang and Tang 2014).

The festival in which the dragon lantern of the Kelao appears has been designated as a National Intangible Heritage. Through that official title, dragon lantern playing is 'restricted' to the Kelao culture in the heritage arena. That has led to an uncomfortable situation in Loushang: Zhou clansmen have to wear Kelao costumes and play the lantern in front of media cameras during the 
Qingming Festival. This performance is misleading for visitors: they fail to appreciate the long-term interaction among the local ethnic groups that helped forge the Han identity in this region.

\section{Intermediary in Heritage Tourism}

Ethnic tourism in Guizhou began in the 1980s and 1990s, and ethnicity has long been a disputed area (Oakes 1995, 1997). In rural society, minorities have long been dominant, which has led to them being prioritised in the designation of official heritage and in tourism investment. As evident in the case of dragon lantern playing, official heritage is designated only in the name of a particular ethnic group-regardless of the ethnic interaction and mutual learning in the region's long social history. Ethnic cultures are authorised and displayed by the tourism company and government: the locals are merely performers. Such an inappropriate presentation of cultural heritage-interpreted not by the community but by other stakeholders-fools the visitor. Another outcome is that the community loses an opportunity to reinforce its own identity by initiating its own celebrations.

The intermediary person plays an interesting role in the contestation. $\mathrm{L}$ is a middle-aged woman from another part of China who many years earlier worked as a voluntary teacher in a local school. Her contribution to the village during her one-year teaching period helped her gain the locals' trust and respect. Having worked in tourism for decades, she acquired considerable experience, and has collected many social resources in that industry, and worked as an active coordinator for tourism investment in Loushang. At the time of the present study, she was employed as manager of a newly established tourism company collectively owned by the Loushang villagers under government supervision. Thus, L was selected by the government for the local community. Her appointment was the result of her close connections with all the stakeholders.

She is a new gentry: she mediates between communities and local governments, which is what the local gentry used to do before the modern time. L has been involved in some disputes with the local government; however, she has been the best intermediary that Loushang has had. She possesses the knowledge to be able to communicate with both sides, and she also knows how to run a business that attracts both tourists and investors. After having conducted several interviews with her, we concluded that her intentions in investing in ethnic tourism for the good of the locals produced a virtuous cycle for all parties. She is the person who coordinates the tourism performance; however, she is still a good facilitator in negotiations among the stakeholders and engaging the community through her knowledge of the local site and communication ability.

\section{Internal Contestation: Social Relations from Within}

In this mountainous habitation and clan society of Loushang, the locals used to hold very similar occupations; the exception was a small number of elders and intellectuals, who worked as clan leaders-notably during disputes among individuals or families ${ }^{12}$ That situation has changed dramatically in recent decades. Young people now leave the area to pursue their education, and they work in different industries. Villagers now have various options for making a living, such as working as tourist guides, running accommodation, and working in restaurants. Currently, within the clan, there are both traditional and new social relations, including clan branches, occupations, age groups, and genders: that has resulted in internal contestation, but it also presents a way of addressing such contestation.

\section{Differential Mode of Association: Conflicts of In- terest among Clan Branches}

Disputes may occur among different branches within a clan: they may be explained by Fei's theory of 'differential mode of association' in traditional Chinese society (Fei 1985). Outsiders are usually unaware of such disputes. As researchers, we initially became aware of the situation when we observed a high frequency of elections for village cadres and staff replacements in restaurants and places of accommodation. After we had been staying there for some time and becoming more warmly regarded, we learned that previously a village cadre had been widely censured for corruption. He had expropriated all the villagers' money that should have been spent on medical insurance: the only exception was his close relatives, for whom he bought insurance. The other families thus had to spend a considerable amount of money for their medical treatment. Such incidents can have a huge impact on clan unity.

Similar instances have, however, occurred in the heritage tourism business. Incumbent cadres generally encourage their close relatives to open tourism businesses. During their three-year terms of office, they have good networking opportunities and possess the social resources to attract customers to such places as restaurants run by their relatives. However, the businesses decline as soon 
as the cadres' terms of office expire. We interviewed a number of former owners of restaurants and lodgings and asked why they had stopped their businesses. They simply responded that customers had ceased to appear. The real reason was related to the social network within the clan. The cadres were interested only in their own establishments and those of close relatives. As a result, not one restaurant or place of accommodation has been in operation for longer than three years (the period of the office term of a village cadre) - even though tourism began at the site almost 16 years ago. This practice constitutes a waste of resources and also has a detrimental effect on local enthusiasm for heritage investment. Villagers may be interested in wishing to increase their incomes through tourism, but they are very cautious owing to the political situation with cadres. These conflicts of interest have a negative impact on locals' attachment to the village.

\section{Gaps between Traditions: Contestations Regard- ing Heritage Practice}

As migrants in a minority region, the Loushang villagers have maintained their Han customs as much as possible. At the same time, they have observed other customs they have learned from neighbouring ethnic groups. These two types of customs may be defined as 'great' and 'little' traditions (see the definition in Redfield 1956) in this remote hamlet: great traditions are ones advocated by intellectuals; little traditions are practiced in daily life. The coexistence of these traditions has led to contestations in heritage practice by people with different educational and occupational backgrounds.

One of the great traditions is 'cultivation and reading', which means that peasants in mountainous areas acquire the ability to read and appreciate Han Chinese classics. A summer school in Han Chinese studies is held for all children of the Zhou clan. The classroom is located next to Zitong Temple, which is the most important public space in the hamlet, underlining its kernel position in the village. The coordinators of the summer school are local intellectuals, who are university and college professors and high regional officials. Many of them moved to the cities, but they are very active in the public affairs of their clan. They possess considerable knowledge about local history and worked on revisions of the Zhou genealogy. They are considered local authorities even though they no longer live in the village. Having heard that we researchers were conducting fieldwork in Loushang, one returned and showed us many places of historical significance. It is their firm intention that their voices be heard.
Clansmen living in the village continue to use traditions in their everyday life. Geomancy is one such tradition. Local geomancers are invited to house construction sites, weddings, and funerals to select propitious times and locations. This geomancy is a blend of Taoist, Buddhist, and Confucian traditions. The space in the village is subject to the practice of geomancy: geomancers determine the layouts in houses for all families. Geomancers are not, however, universally regarded as honourable professionals, and they have a poor living. Unlike the local intellectuals, who established the summer school and encourage young people to pursue a course that will lead to their own advancement, geomancers maintain a low profileespecially in public affairs. We held a brief interview with one geomancer, who was delighted with our interest in his work. We planned to continue the interview the following day. However, when we arrived to conduct the second interview, he suddenly declined: he had discovered that we were working closely with a local intellectual, who had been a classmate of his but now led a much better life.

At the summer school, almost all the students were taught history. All the families sought geomancers' advice about the timing of various events and siting of structures. Both Han Chinese studies and geomancy are indispensable for local life in Loushang: the former offers a philosophy for ideal living; the latter is applied in everyday life. The two are inseparable for maintaining the Han identity in remote Southwest China. However, the two traditions are at odds with each other in the area of heritage practice and other public affairs: that is especially true when the practitioners have different occupations and powers of discourse. The intellectuals are more proactive in presenting their own opinions. By contrast, geomancers talk in a lower voice-especially when they feel subject to peer pressure. However, the attitudes and opinions of both have to be presented to create an integrated image of this rural heritage site.

\section{Local Youths as Intermediaries}

The above internal contestation has its origins in two types of social relations within the community. The first arises as a result of population growth when a branch of the clan receives preferential benefits at the expense of the entire clan. The second is more severe now: there are more local employment options than simply being peasants in the mountains. The social hierarchy tears down homogeneity and leads to priorities emerging in heritage practice and local development. The internal contestation has a negative effect on local attachment among residents. This 
hamlet is no longer the primary home of the clansmen: they may have turn to their own clan branches or social associations to achieve a sense of belonging. We searched for a solution to this contestation by means of a third social relationship: age.

Young people from different families will become future owners of the village; at present, they can serve as intermediaries among the contesting social groups within the clan. The young people taught us heritage experts about local traditions and helped in communicating with the elders. They have learned more about their own culture through listening to the elders while also understanding our strategies towards conservation and development. Those young people possess knowledge of the past as well as open minds towards a better future. More importantly, they currently have few interest distractions: they can work together to persuade their family members in a positive way, thereby breaking the barriers among social gaps. Born and working locally, they are the best intermediaries in heritage management.

\section{Negotiating the Contestations: Engaging the Community in Heritage Management}

The contestations within the community and among the stakeholders need to be negotiated by empowering the locals in heritage management. We identified intermediaries in the form of local young people for internal contestation and $\mathrm{L}$ for external contestation.

\section{Empowerment through Collaborative Curation}

To engage the community and present the heritage value of Loushang, we organised two exhibitions about the local culture and its history ${ }^{13}$. The exhibitions were commissioned by the local government, with whom we intend to collaborate in community work. The aim with the exhibitions is that residents should interpret their own heritage and work together in heritage practice, thereby reinforcing their local attachment and helping address internal contestations.

First, we had to select exhibition sites that could also be used as communal spaces for the villagers. Accordingly, we consulted with residents in deciding where they found most appropriate. The young volunteers informed us of their opinions; in turn, they asked for those of their elders. Finally, we selected two locations. The first was Zitong Temple and its affiliated buildings in the upper part of the hamlet. The old buildings are to be renovated for the exhibition and will serve as a public space for residents living nearby. The hamlet is, however, situated on a mountainside, and it would be inconvenient for older residents to have to climb up and down to reach the sole public space at the temple. Accordingly, a second exhibition hall is to be built in the lower part of Loushang. The locals will be encouraged to use those places for casual meetings and seasonal events (Figure 5). The two halls will be different from the typical exhibition halls in China's ethnic villages of so-called eco-museums, which are usually situated at the end of the village and distant from the locals' daily life.

The temple space will present local history-not in the form of an authorised history, but stories told by the community itself. Changes that have occurred in local life will also be presented, such as who was the first Loushang resident to go to college and when the houses first received power and water supplies. Thus, the local community is the potential audience: residents will be able to learn about their own history by spending time in the exhibition halls. The exhibition space in the lower part of the hamlet will present local culture, for example, interaction among the ethnic groups, water management in upland farming, and rural landscape of mountainous farming. The space will address the living wisdom in this Han migrant settlement, revealing their unique identity in this remote minority region. By curating the exhibitions and with the help of local young people, we aim to facilitate communication among the different social groups there. The exhibitions will be a way to empower the locals and help them listen to different voices. We will present all their ideas equally concerning their shared heritage: no specific customs or traditions will be prioritised.

\section{Local Development rather than Heritage Tourism}

The key to negotiating external contestation lies in balancing the demands and benefits of different stakeholders through overall local development. Tourism is one means of achieving that. The tourism company (currently serving as the main manager of the site) should engage the community in other industries. The company manager, L, plays a crucial part in this engagement.

As a good friend of the Loushang community, L has taken the locals' demands seriously. At the same time, her plans for the site may be affected by the aims of the local government. L took part in performances in Dong costume in the early 2000s. She was also the coordinator of the Qingming Festival in recent years. She has experienced the strategic changes in heritage tourism in Loushang. In one interview, she suggested that based on her experience, the village could be promoted as a living piece of history, 


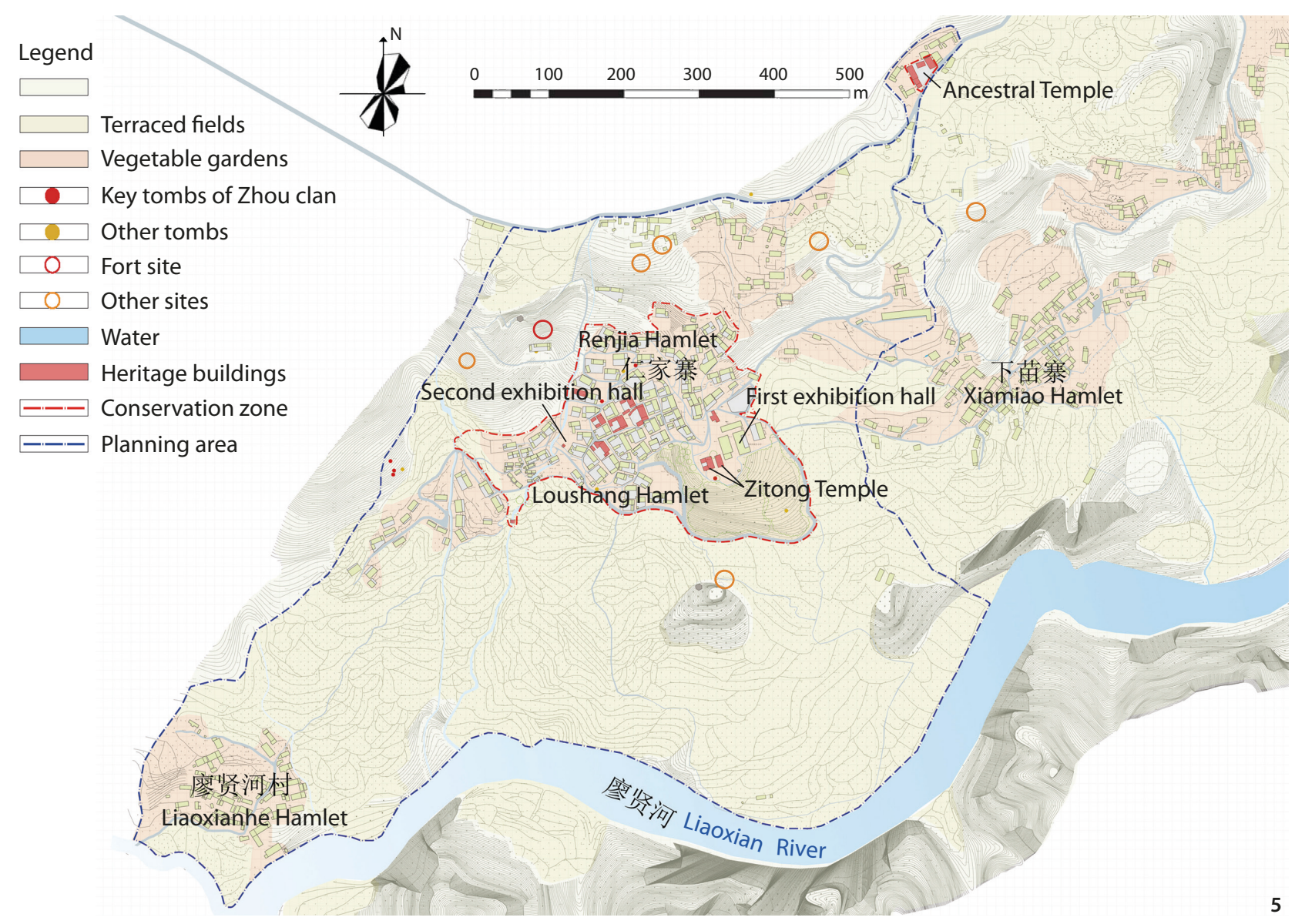

Figure 5 Map of Loushang with indications of possible locations of the exhibition halls (Source: Loushang conservation master plan team).

frozen in time. Hearing this, I immediately asked her what she thought about her former students and what the village would then mean for their future. She was unable to respond to the question: she really loves those former students and has high hopes for their future lives. My question probably reminded her of the locals' necessity to take part in decision making. Subsequently, the tourism company decided to make the strategic change to invest in eco-agriculture, rather than transforming Loushang into a dead monument without a promising future. Collective ownership of the company stimulates the community to collaborate in local development. Multiple industrial development is important: it reduces investment risks and also diverts pressure away from the tourism capacity. L's connections with the community and local government as well as her social networking in the region facilitate industrial development. The products such as organic rice and vegetables are well distributed and sell well.

As a living settlement open to the future, the Loushang community may expand beyond just the clansmen. In the future, more people may join the community: outsiders will probably move in and become 'local'. L was one such person, and perhaps some cadres from outside the hamlet and industrial investors will also join the community. These potential social changes represent both challenges and opportunities for Loushang. The young people, who are more open minded than the elders, will be important in taking in these outsiders, internalising their identities, and establishing their attachment among all the locals.

\section{Conclusions}

This case study of Loushang reveals that different social relations in rural heritage sites lead to internal and external contestations. Such contestations are rooted in both the distant and recent social history of interaction among its ethnic groups as well as in relations between the local community and local government. New stakeholders emerged as soon as Loushang was designated as an official heritage and became a tourist attraction, thereby producing fresh conflicts. Not all the contestations were unhealthy. To some extent, the internal contestation created a vitality and sustainability for this rural village; the external contestation enriched the complexity of heritage 
management. Nevertheless, conflicts may cause problems in attachment and identity, which are interconnected notions. It is essential to identify such contestations, assess their causes and impacts, and negotiate accordingly among the affected social groups.

Heritage experts often consider themselves facilitators in management and negotiation (Smith 2006; Baillie 2009). This paper examines intermediaries, who can negotiate contestations better than heritage experts: intermediaries are actors who can manage on-site heritage every day. They are or will become locals: through intermediaries, communication and mutual understanding can be established within the community and among stakeholders. Intermediaries are key figures to achieve collaboration in such projects as curation of local history initiated by the local government and building new industries financed by a tourism company. Such actions present an indirect way to empower the community in communityoriented heritage management. Heritage practitioners and other outsiders should offer professional suggestions but not decide on the part of the community. Only through a community having an enlarged, deepened understanding of the world and diverse ways of development can it make better choices for itself and its heritage (Sen 2001).

It is important to employ proper methods to communicate, facilitate, and empower. Interdisciplinary approaches were applied in the case of Loushang, providing theoretical support for heritage practice. Professional heritage work cannot be achieved by armchair strategists; it can come only through long-term fieldwork among locals, which can permit the identification of contestations and appropriate individuals to be intermediaries in negotiations among social groups. We achieved success in engaging Loushang locals to collaborate in daily management, such as curation and eco-friendly industries; however, our proposals to invite local residents to our presentations about conservation work for Loushang to the local government were constantly refused by the county cadres. At the time of writing, the community is still unable to take part in such official meetings. The diversity produced by new residents and the present young people becoming older may offer better chances to enhance participation and rights in the future as well as to help make independent decisions.

\section{Notes}

1. Evident in the Cultural Relics Protection Law of the People's Republic of China (2017).

2. The data were mainly collected in fieldwork conducted by the Centre for Land and Cultural Resources Research at Fudan University. I was assigned as a major planner with a group of heritage experts to compile a conservation master plan for the village under the title 'Priority Protected Site at National Level'. The work began in summer 2016 and was evaluated in early 2019.

3. This is required by 'The Principles for the Conservation of Heritage Sites in China' (2014) and generally carried out by the local government of county level under supervision of the State Administration of Cultural Heritage.

4. In the case of Priority Protected Site at National Level, the budget is mainly assigned from the national government to the local government of the county level.

5. In addition to academic studies, this trend is evident in many national policies in recent years such as that of Beautiful Countryside in 2014 and strategy of Rural Revitalisation in 2017.

6. It is according to the author's own working experience and observation in such institutions.

7. The demographic data were collected during fieldwork in August, 2016.

8. The genealogy was compiled by the clansmen in 2008 based on dozens of different ancient versions in Qing and the Republic times.

9. The Zhou ancestors may have bought the land from a land agent. According to local oral accounts, the Miao may have been driven away from the land. This explanation of events is evident in several place names around the village.

10. According to interviews with Zhou residents in 2016.

11. According to interviews with Zhou residents in 2016.

12. According to the Zhou genealogy.

13. The curation was still under preparation at the time of writing.

\section{Acknowledgement}

I owe my gratitude to the team members of the conservation master plan for Loushang, including but not limitied to, Prof. Xiaofan Du, Dr. Da Kong, and Keshuo Cao. I am grateful for the kind help and suggestions of the journal editors and the peer reviewers.

\section{References}

Baillie, Britt. 2009. Living Heritage Approach Handbook. Rome: ICCROM. 
Carlarne, John. 2011. "Multi-context Engaged Learning and Ethnographic Fieldwork: Some Notes from the Middle of the Edge." International Journal of Social Research Methodology 14 (2): 135-152.

Fei, Xiaotong. 1985. Xiangtu Zhongguo [From the Soil: The Foundations of Chinese Society]. Shanghai: SDX Joint Publishing Company.

Harrison, Rodney. 2013. Heritage: Critical Approaches. Abingdon \& New York: Routledge.

Li, Fengqing, and Jianxin Wang. 2013. "Wenhua yichandi ziyuan guanli zhong liyi xiangguan zhe canyu jiegou guanxi tanxi." [The Structural Analysis of Stakeholder Participating the Heritage Site Resource Management] Journal of Northwest University (Humanities and Social Sciences Edition) 43 (2): 132-136.

Luo, Deyin. 2016. "Rang xiangcun yichan huigui baixing shenghuo." [Let Rural Heritage Return to People's Life.] New Architecture, no. 4: 18-22.

Oakes, Tim. 1995. “Tourism in Guizhou: The Legacy of Internal Colonialism." In Tourism in China: Geographic, Political, and Economic Perspectives, edited by Alan A. Lew and Lawrence Yu, 203-220. Boulder: Westerview Press.

Oakes, Tim. 1997. "Ethnic Tourism in Rural Guizhou: Sense of Place and Commerce of Authenticity." In Tourism, Ethnicity, and the State in Asian and Pacific Societies, edited by Michel Picard and Robert Wood, 35-70. Honolulu: University of Hawaii Press.

Oakes, Tim. 2006. "Cultural Strategies of Development: Implications for Village Governance in China." The Pacific Review 19 (1): 13-37.

Oakes, Tim. 2009. "Cultural Geography and Chinese Ethnic Tourism." Journal of Cultural Geography 12 (2): 3-17.

Oakes, Tim. 2010. "Dragonheads and Needlework: Textile Work and Cultural Heritage in a Guizhou County." Provincial China 7 (2): 151-177.

Oakes, Tim. 2013. "Heritage as Improvement: Cultural Display and Contested Governance in Rural China." Modern China 39 (4): 380-407.

Oakes, Tim. 2016. "Villagizing the City: Turning Rural Ethnic Heritage into Urban Modernity in Southwest China.” International Journal of Heritage Studies 22 (10): 751-765.

Redfield, Robert. 1956. Peasant Society and Culture: An Anthropological Approach to Civilization. Chicago: University of Chicago Press.

Riesto, Svava, and Anne Tietjen. 2016. “Doing Heritage Together: New Heritage Frontiers in Collaborative
Planning." In Heritage, Democracy and the Public: Nordic Approaches, edited by Trogrim Sneve Guttormsen and Grete Swensen, 159-174. Farnham: Ashgate Publishing Limited.

Sen, Amertya. 2001. Development as Freedom. Oxford: Oxford University Press.

Shi, Jizhong. 1990. “Guizhou Hanzu yimin kao.” [Study on Han Migrants in Guizhou.] Guizhou Wenshi Congkan no. 1: 26-33.

Smith, Laurajane. 2006. Uses of Heritage. London: Routledge.

Stevens, Mary, Andrew Flinn, and Elizabeth Shepherd. 2010. "New Frameworks for Community Engagement in the Archive Sector: From Handing over to Handing on." International Journal of Heritage Studies 16 (1-2): 59-76.

Tapp, Nicholas. 2008. "Romanticism in China?-Its Implications for Minority Images and Aspirations." Asian Studies Review 32 (4): 457-474.

Tapp, Nicholas. 2010. "Yunnan: Ethnicity and Economies-Markets and Mobility". The Asia Pacific Journal of Anthropology 11 (2): 97-110.

Tapp, Nicholas. 2014. "Religious Issues in China's Rural Development: The Importance of Ethnic Minorities." The Asia Pacific Journal of Anthropology 15 (5): 433452.

Urla, Jaqueline, and Justin Helepololei. 2014. "The Ethnography of Resistance Then and Now: On Thickness and Activist Engagement in the Twenty-First Century." History and Anthropology 25 (4): 431-451.

Wang, Cangbai. 2017. "Heritage as Theatre: Reconceptualizing Heritage-Making in Urban China." China Information 31 (2): 195-215.

Wang, Zheng. 2016. "Jiyu zhibu lilun de chuantong cunluo baohu fazhan guihua celve yanjiu." [Traditional Village Protection Development Planning Strategy Based on the Theory of the Weaving Analysis.] Master diss., Beijing University of Technology.

Yan, Haiming. 2012. "World Heritage in China: Universal Discourse and National Culture." PhD diss., University of Virginia.

Yan, Haiming. 2015. "World Heritage as Discourse: Knowledge, Discipline and Dissonance in Fujian Tulou Sites." International Journal of Heritage Studies 21 (1): 65-80.

Yu, Hua. 2015. "A Vernacular Way of 'Safeguarding' Intangible Heritage: The Fall and Rise of Rituals in Gouliang Miao village." International Journal of Heritage Studies 21 (10): 1016-1035. 
Zhang, Changnian, Zhankun Wang, and Wenjie Tang. 2014. "Shaoshu mimzu chuantong tiyu de wenhua xiangzheng yu shehui gongneng tanjiu-yi Gelaozu wu maolong weili." [Cultural Symbols and Social Functions of Traditional Ethnic Minority Sports: A Case Study of Gelao Long Hair Dragon Dance.] Journal of Nanjing Sport Institute (Social Science) 28 (5): 29-34.

Zhu, Yujie. 2015. "Cultural Effects of Authenticity: Contested Heritage Practices in China." International Journal of Heritage Studies 21 (6): 594-608. 